\title{
Bovine Genome Analysis to Unravel the Location and Feature of Target Sites of RNA-Guided Hyperactivated Recombinase Gin with Spacer Length Six
}

Shalu Kumari Pathak, Arvind Sonwane, Subodh Kumar

10.18805/IJAR.B-4693

\begin{abstract}
Background: Programmable nucleases are very promising tools of genome editing (GE), but they suffer from limitations including potential risk of genotoxicity which led to the exploration of safer approach of GE based on RNA-guided recombinase (RGR) platform. RNA-guided recombinase (RGR) platform operates on a typical recognition or target site comprised of the minimal pseudo-core recombinase site, a 5 to 6 -base pair spacer flanking it and whole this central region is flanked by two guide RNA-specified DNA sequences or Cas 9 binding sites followed by protospacer adjacent motifs (PAMs).

Methods: The current study focuses on analysis of entire cattle genome to prepare a detailed map of target sites for RNA-guided hyperactivated recombinase Gin with spacer length six. For this, chromosome wise whole genomic sequence data was retrieved from Ensembl. After that search pattern for recombinase Gin with spacer length six was designed. By using this search pattern, RGR target sites were located by using dreg program of Emboss package.

Result: Total number of RGR target sites identified in bovine genome for recombinase Gin was 677 with spacer length six. It was also investigated that whether these RGR target sites are present with in any gene or not and it was found that RGR target sites lies in both genic and intergenic region. Besides this, description of genes in context with these target sites was identified.
\end{abstract}

Key words: Cattle genome, Gin, Gene description, Hyperactivated recombinase, RNA-guided, Spacer length.

\section{INTRODUCTION}

Recombinases are powerful tools for genetic modifications, but often require complex directed-evolution experiments to retarget specificity and are limited by lack of userprogrammability. Hence, to address these constraints, modified site-specific recombinases which have 'relaxed' substrate specificity called as hyperactivated recombinases have been developed. To address the limitation of lack of user-programmability, RNA-guided recombinase platform (RGR) has been developed. This platform operates on a typical recognition site which envisages a minimal pseudocore recombinase site, a 5 to 6-base pair spacer flanking it and whole this central region being flanked by two guide RNA-specified DNA sequences or Cas9 binding sites followed by protospacer adjacent motifs (PAMs).

Though only one RGR platform based on hyperactivated recombinase $\operatorname{Gin}(\beta)$ is available currently, more hyperactivated recombinases have been evaluated as part of ZFR platforms (Gaj et al., 2013; Sirk et al., 2014). In case of Gin itself, four more ( $\alpha, \gamma, \delta, \varepsilon$ and $\zeta$ ) hyperactivated versions have been evaluated (Gaj et al., 2013). Sirk et al. (2014) described functionality of ZFR platforms based on $\beta$ and $\operatorname{Sin}$ hyperactivated recombinases. Information may pour in for some new hyperactivated recombinases in the future. This will be useful since more number of hyperactivated recombinases will increase the overall targeting capacity of recombinase-based or RGR platform based genome editing. RGR target sites for the RGR platforms based on the hyperactivated recombinases other than $\operatorname{Gin}(\beta)$ can be
Division of Animal Genetics, Indian Veterinary Research Institute, Izatnagar, Bareilly-243 122, Uttar Pradesh, India.

Corresponding Author: Shalu Kumari Pathak, Division of Animal Genetics, Indian Veterinary Research Institute, Izatnagar, Bareilly243 122, Uttar Pradesh, India. Email: skpathakvet@gmail.com

How to cite this article: Pathak, S.K., Sonwane, A., Kumar, S. (2022). Bovine Genome Analysis to Unravel the Location and Feature of Target Sites of RNA-Guided Hyperactivated Recombinase Gin with Spacer Length Six. Indian Journal of Animal Research. DOI: 10.18805/IJAR.B-4693.

Submitted: 26-06-2021 Accepted: 30-10-2021 Online: 07-01-2022

easily discerned by only replacing the central 20 bppseudorecognition sequence in the target sequence with that for the other hyperactivated recombinase (Chaikind et al., 2016).

RNA guided recombinase platform may also be utilized for study or treatment of genetic diseases similar to RNA guide endonuclease based platform. A candidate SNP allele for African swine fever virus resilience T1591C of p65 has been introgressed from warthog to the genome of conventional swine cells (Palgrave et al., 2011). Isoleucyl-tRNA synthetase (IARS) syndrome is a recessive disease of Japanese Black cattle caused by a single nucleotide substitution. Ikeda et al. (2017) have reported correction of disease mutation using CRISPR/Cas9-assisted genome editing.

RNA-guided recombinase (RGR) platform, having its ability to carry out efficient, reliable and safe genome editing, has a great potential in genome modifications for animal 
breeding and may become a tool of choice for this purpose in the future. However, application of genome editing in animal breeding through RGR will become reality only after we overcome two critical challenges. These include accurate information about the Quantitative trait nucleotides (QTNs) for a particular trait or set of traits and the detailed map of RGR target sites throughout the genomes of livestock species. It is certain that the first challenge would be overcome because of the current era of genomics and ongoing GWAS studies as well as application of GS in animal breeding since we will come to know various QTNs through this. Overcoming the second challenge pertaining to RGR target sites would include preparation of detailed maps for target sites of available RGR platforms as well as RGR platforms that can be constructed in future based on other evaluated hyperactivated recombinases in genomes of different livestock species. The present study would contribute in addressing the second challenge wherein a detailed map of target sites for hyperactivated recombinases Gin with spacer length six was prepared and genes in context to RGR target sites were identified in entire cattle genome (Bos taurus).

\section{MATERIALS AND METHODS}

The experiment was conducted during $\mathrm{PhD}$ research session 2017 -18 and 2018-19 at Indian Veterinary Research Institute, Izatnagar, Bareilly, Uttar Pradesh. Chromosome wise whole genomic sequence data was retrieved from Ensembl (Bos_taurus.UMD3.1.dna.chromosome). Search pattern was designed depending on structure of RGR target site which includes degenerate sequence of 20 bp core recombinase recognition sites (NNNNAAASSWWSSTTT NNNN) flanked by spacer ( 6 bases), guide RNA binding site ( 25 bases) and PAM sequences at both the ends. Designed search pattern was as follows:

CC[ATCG][ATCG][ATCG][ATCG][ATCG][ATCG][ATCG ][ATCG][ATCG][ATCG][ATCG][ATCG][ATCG][ATCG][ATC
G][ATCG][ATCG][ATCG][ATCG][ATCG][ATCG][AT CG][ATCG][ATCG][ATCG][ATCG][ATCG][ATCG][ATC G][ATCG][ATCG]AAA[TCG][ATCG][AT][AT][ATCG][ACG] TTT[ATCG][ATCG][ATCG][ATCG][ATCG][ATCG][ATC G][ATCG][ATCG][ATCG][ATCG][ATCG][ATCG][A TCG][ATCG][ATCG][ATCG][ATCG][ATCG][ATCG][ATC G][ATCG][ATCG][ATCG][ATCG][ATCG][ATCG] [ATCG][ATCG][ATCG][ATCG]GG.

Genomic sequence data and search pattern was loaded to dreg program of Emboss package individually for each chromosome and target Sites for Rna-guided recombinase (RGR) were identified throughout the bovine genome. All identified RNA guided recombinase target sites were converted into Fasta format. Fasta sequences were mapped against RefSeq Genome Database (refseq genomes) of Bos Taurus (taxid: 9913) for highly similar sequences by using Blast of NCBI. Sequences (Subject sequence) having $100 \%$ alignment along with no gap with RGR target site sequences (Query sequence) were selected and features of these sites were identified.

\section{RESULTS AND DISCUSSION}

In present investigation, six hundred and seventy seven (677) RNA-guided recombinase target sites were identified in bovine genome (Table 1). On mapping these sequences against RefSeq Genome Database of Bos Taurus (taxid: 9913) for highly similar sequences through Blast, it was found that 247 RGR target sites lie in genic region and 430 in intergenic region. Location and features of important target Sites identified in genic region of bovine genome for hyperactivated recombinase gin with spacer length six has been shown in Table 2.

In present study, whole genome of bovine (Bos taurus) was analyzed to identify the location of target sites for hyperactivated recombinase Gin with spacer length six. It was found that RGR target sites are located in several

Table 1: Chromosomal distribution of RGR target sites in bovine genome.

\begin{tabular}{|c|c|c|c|c|c|}
\hline $\begin{array}{l}\text { Chromosome } \\
\text { no. }\end{array}$ & $\begin{array}{l}\text { Size } \\
\text { (MB) }\end{array}$ & $\begin{array}{c}\text { RGR target } \\
\text { sites no. }\end{array}$ & $\begin{array}{c}\text { Chromosome } \\
\text { no. }\end{array}$ & $\begin{array}{l}\text { Size } \\
(\mathrm{MB})\end{array}$ & $\begin{array}{c}\text { RGR target } \\
\text { sites no. }\end{array}$ \\
\hline 1 & 45.6 & 42 & 16 & 23.6 & 16 \\
\hline 2 & 39.6 & 45 & 17 & 21.7 & 28 \\
\hline 3 & 35 & 27 & 18 & 19.1 & 21 \\
\hline 4 & 34.8 & 36 & 19 & 18.5 & 11 \\
\hline 5 & 34.9 & 29 & 20 & 20.8 & 23 \\
\hline 6 & 34.2 & 28 & 21 & 20.6 & 13 \\
\hline 7 & 32.2 & 27 & 22 & 17.8 & 18 \\
\hline 8 & 32.6 & 34 & 23 & 15.2 & 10 \\
\hline 9 & 30.5 & 31 & 24 & 18.2 & 15 \\
\hline 10 & 30.1 & 28 & 25 & 12.4 & 14 \\
\hline 11 & 31 & 20 & 26 & 14.9 & 13 \\
\hline 12 & 26.2 & 14 & 27 & 13 & 11 \\
\hline 13 & 24.4 & 20 & 28 & 13.4 & 14 \\
\hline 14 & 24.3 & 26 & 29 & 14.8 & 6 \\
\hline 15 & 24.5 & 24 & $x$ & 42.1 & 33 \\
\hline
\end{tabular}


Bovine Genome Analysis to Unravel the Location and Feature of Target Sites of RNA-Guided Hyperactivated Recombinase...

Table 2: Location and features of important target sites identified in genic region of bovine genome for hyperactivated recombinase gin with spacer length six.

\begin{tabular}{|c|c|c|c|c|}
\hline Chr. no. & Start position & End position & RGR target site sequence & Gene description \\
\hline 1 & 75184537 & 75184614 & $\begin{array}{l}\text { CCTGGGAAGCCCTCAGTGGGTTAAAAG } \\
\text { AGCATTAAACATTGATTTGCTCATAAAGT } \\
\text { TTCTTGGAATCAGGTGTTTGGG }\end{array}$ & Protein MB21D2 \\
\hline 2 & 36257786 & 36257863 & $\begin{array}{l}\text { CCAGAGCTCATGGAGGTGATCTTTTCTC } \\
\text { AAGTTAAACATACGTTTAATTTCAGTATC } \\
\text { ATAGTTCTATTCCATCTGGGG }\end{array}$ & Integrin beta- 6 isoform $\mathrm{X} 1$ \\
\hline 2 & 86895761 & 86895838 & $\begin{array}{l}\text { CCAATCCCGGTCCTCAGAGAGCTTCAG } \\
\text { TTTCTGAAACTTAAGTTTATTTCTATGATA } \\
\text { TCTTGTTCCTGTAGGCACAGG }\end{array}$ & Inactive phospholipase C-like protein 1 \\
\hline 5 & 1.17E+08 & 1.17E+08 & $\begin{array}{l}\text { CCCCAAAAGCCAGTAAACAGGGCAGTT } \\
\text { TGGTGGAAAGGAAAGTTTGCTGTATTTT } \\
\text { TGGTGCCTGCAACTGGACAGGGG }\end{array}$ & Fibulin-1 precursor \\
\hline 8 & 38011499 & 38011576 & $\begin{array}{l}\text { CCAATTTTTCCAGGGCTAGAGACCTTCT } \\
\text { TCTTTAAAGAAATCTTTAAACCAAACACT } \\
\text { GAAGGCTTGGGTTTTCCCAGG }\end{array}$ & Lysine-specific demethylase $4 \mathrm{C}$ \\
\hline 10 & 49024876 & 49024953 & $\begin{array}{l}\text { CCATGTATGTTCATCTCTGTGCAAGTAG } \\
\text { CTCCAAAAGGAATATTTTTTTAATTTTAA } \\
\text { AAATTTATTTTTAATTGAAGG }\end{array}$ & Nuclear receptor ROR-alpha \\
\hline 11 & 82979748 & 82979825 & $\begin{array}{l}\text { CCAAGTAAATACAGAACTTTGAGGTACT } \\
\text { AAACAAAACGTTAGTTTTGTTTCAAGGT } \\
\text { TAAACATGTTTGTCACAGTAGG }\end{array}$ & Neuroblastoma-amplified sequence \\
\hline 12 & 76804827 & 76804904 & $\begin{array}{l}\text { CCCAAGCTGGCTTGTTTTTTTTAAGTTT } \\
\text { TTTTAAAATGAAGATTTGATGGATAGCAT } \\
\text { GAGAGAAAGGGAGGGGTGTGG }\end{array}$ & Claudin-10 isoform b \\
\hline 14 & 9134518 & 9134595 & $\begin{array}{l}\text { ССТСТTTTССTGCATCATCTCACTTAACC } \\
\text { CTCAAAACAATCCTTTACAAGAGGTATTG } \\
\text { TTGGCATCCTTGTTGAAGGG }\end{array}$ & Protein NDRG1 \\
\hline 14 & 9368738 & 9368815 & $\begin{array}{l}\text { CCTAAAGTGACTTCATGCTTTAAGGGGG } \\
\text { AAAAAAAATCTTCCTTTATTTGCTCTGAT } \\
\text { TGTCAGCTATTGCATTTAAGG }\end{array}$ & Thyroglobulin precursor \\
\hline 15 & 57904828 & 57904905 & $\begin{array}{l}\text { CCTTTTTAGTGCTCTGTGTCTCTATGCT } \\
\text { GCATGAAATATTAATTTTTTTGGAAAATG } \\
\text { AGCTACTTATTATTTTATTGG }\end{array}$ & Anoctamin-3 \\
\hline 16 & 67622051 & 67622128 & $\begin{array}{l}\text { CCTATTTATACTAAAGAGAAAACAAAGTA } \\
\text { GAAAAAACTTAACTTTTCTGAGTGGTAA } \\
\text { GTATAAACCTAGCTTCCATGG }\end{array}$ & TRMT1-like protein \\
\hline 17 & 17477131 & 17477208 & $\begin{array}{l}\text { CCTACAGGAACATGATTAAAGGATTAAA } \\
\text { TGAAAAAAGTATTATTTCATGAACATAAA } \\
\text { TGATATAAATAAGGGACGAGG }\end{array}$ & $\begin{array}{l}\text { GRB2-associated-binding protein } 1 \\
\text { isoform X1 }\end{array}$ \\
\hline 18 & 29716848 & 29716925 & $\begin{array}{l}\text { CCATGCACAACAACAAAGACAAAGCAC } \\
\text { AGCCAAAAATAAAGCTTTTAAAAAAATT } \\
\text { AAAAATATTTGAAAATCACATGG }\end{array}$ & Cadherin-8 isoform $\mathrm{X} 1$ \\
\hline 18 & 36983798 & 36983875 & $\begin{array}{l}\text { CCCTTGAGATTTTGTTGGAATCCTGACG } \\
\text { TATGTAAAGTTTCCTTTATGGAGAATTTC } \\
\text { ATACTGATTCTTCCTACACGG }\end{array}$ & $\begin{array}{l}\text { NEDD4-like E3 ubiquitin-protein ligase } \\
\text { WWP2 }\end{array}$ \\
\hline 20 & 31891235 & 31891312 & $\begin{array}{l}\text { CCTGCTGGTGTAATGTCGCTTACCTGGG } \\
\text { CATAAAAATCAATGTTTGCCAATGAACTT }\end{array}$ & Growth hormone receptor precursor \\
\hline
\end{tabular}

Table 2: Continue..... 
Bovine Genome Analysis to Unravel the Location and Feature of Target Sites of RNA-Guided Hyperactivated Recombinase...

Table 2: Continue.....

20

62038715

62038792

8045598

8045675

24

25

26700954

26701031

26

$34327821 \quad 34327896$
GGATTGCTGAGCTGTGTATGG

CCTATCTATTTTGAGTTACTATGGGGTTG

GCCAAAACGTTCATTTGATGGTACCAAA

AAACCCAAACGAGCCTTTTGG

СССТTСТTССТАСTTAAGTAAAAAAGGG

AAAGGCAAAGGAATCTTTATTTCCCTTG

GTATCAATGTAAAAGTAACTTGG

CCACATGTGCCGCACCTAAGACCCTGA

GCAGCCAAATGAATATTTAAAAATGGGG

CCAGGGGGCTCACCTTTTCCTGG

CСТTTTCAATTATTCCTACCATTTTCTTAA

AAAAATATTCATTTATTTATTTGGTTGTGC

TGGGTCTTAGTTGGGG
Catenin delta-2 isoform $\mathrm{X} 1$

Docking protein 6

Kinesin-like protein KIF22

Hyaluronan-binding protein 2 precursor important protein coding genes which regulates important biological proteins like Mab-21 domain containing 2, integrin beta- 6 isoform $\times 1$, fibulin-1 precursor, thyroglobulin precursor, kinesin-like protein KIF22, Raftlin protein, inactive phospholipase C-like protein 1 , docking protein 6 , growth hormone receptor precursor, lysine-specific demethylase 4C, TRMT1-like protein, GRB2-associated-binding protein 1 isoform $X 1$, cadherin-8 isoform $X 1$, hyaluronan-binding protein 2 precursor, claudin-10 isoform $b$, nuclear receptor ROR-alpha, neuroblastoma-amplified sequence, protein NDRG1, anoctamin-3, NEDD4-like E3 ubiquitin-protein ligase WWP2, catenin delta-2 isoform X1 etc.

A RGR site in gene MB21D2 coding for Mab-21 domain containing 2 was located on chromosome 1. Olivieri et al. (2016) studied to identify genomic regions and metabolic pathways associated with dry matter intake, average daily gain, feed efficiency and residual feed intake in an experimental Nellore cattle population and found the association of MB21D2 gene with average daily gain. An et al. (2018) identified loci and candidate genes for internal organ weights in Simmental beef cattle by genome-wide association study. They found that polymorphism in MB21D2 gene is associated with kidney weight.

A RGR site in gene ITGB6 coding for integrin beta-6 was located on chromosome 2 . The encoded macromolecule forms a dimer with alpha $v$ chain and this heterodimer may bind to ligands like fibronectin and transforming growth factor beta one. These can function as receptors for foot-andmouth disease virus (FMDV) in epithelium. Berryman et al. (2005) have shown that 'foot-and-mouth disease virus (FMDV) infection mediated by the integrin takes place through clathrin-dependent endocytosis however not caveolae or alternative endocytic pathways that rely upon lipoid rafts. A RGR site in gene coding for fibulin-1 precursor was located on chromosome 5. Fibulin-1 may play a role in cell adhesion and migration along protein fibers within the extracellular matrix (ECM). It might be vital for development related processes and contribute to the supramolecular organization of basement membranes. Debber et al. (2002) reported that fibulin-1 gene (FBLN1) is disrupted in a reciprocal chromosomal translocation $t(12 ; 22)$ which is associated with a complex type of synpolydactyly.

A RGR site in gene coding for thyroglobulin precursor was located on chromosome 14. Thyroid hormones regulates metabolism and affect the homeostasis of fat deposition. The sequence coding iodoprotein (TG), producing the precursor for thyroid hormones, has been proposed as a positional and functional candidate gene for a QTL with an effect on fat deposition. Gan et al. (2008) identified 6 novel SNPs at the 3' flanking region of the TG gene. The SNP marker association analysis indicated that the SNP markers were significantly associated with marbling score. They prompt that theTG-gene-specific SNP is also a helpful marker for meat quality traits in future markerassisted selection programmes in Bos taurus. A RGR site in gene KIF22 encoding kinesin-like protein KIF22 was located on chromosome 25 . It is involved in spindle formation and the movements of chromosomes during mitosis and meiosis. It binds to microtubules and to DNA. A RGR site in gene coding for raftlin isoform $X 3$ was located on chromosome 1. Raftlin protein is pivotal for maintenance of lipid rafts and may be involved in regulation of $B$ cell antigen receptor mediated signaling (Saeki et al., 2003). Raftlin promotes binding of double stranded RNA, activations of B cell receptors and toll like receptor 3 signaling pathways and is involved in IL 17 production to release pro inflammatory cytokines. Qu et al. (2017) investigated differentially expressed membrane proteins of pulmonary alveolar macrophages infected with highly pathogenic porcine reproductive and respiratory syndrome virus and its attenuated strain by label free quantitative proteomic analysis and found higher abundance of raftlin in the HP PRRSV group compared to the AP PRRSV and control groups which explain the more severe inflammation triggered by HP PRRSV.

A RGR site in gene PLCL1 coding for inactive phospholipase C-like protein 1 was located on chromosome 2. It is involved in an inositol phospholipid-based intracellular signaling cascade. It regulates the turnover of receptors and thus contributes to the maintenance of GABA-mediated 
synaptic inhibition. Its aberrant expression might contribute to the genesis and progression of respiratory organ malignant neoplastic disease. Asano et al. (2014) investigated the role of phospholipase C-related catalytically inactive protein (PRIP) in insulin granule exocytosis using Prip-knockdown mouse insulinoma (MIN6) cells and demonstrated that PRIP regulate KIF5B-mediated insulin secretion. It was found that insulin release from Prip-knockdown MIN6 cells was higher than that from control cells.

A RGR site in gene KDM4C coding for lysine-specific demethylase $4 \mathrm{C}$ was located on chromosome 8 . The encoded super molecule could be a trimethylation-specific demethylase and converts specific trimethylated histone residues to the dimethylated type. This enzymatic action regulates gene expression and chromosome segregation. KDM4C is induced during adipocyte differentiation and depletion of KDM4C is sufficient to block this kind of cellular differentiation (Lu et al., 2012). KDM4C is amplified or upregulated in several cell lines derived from esophageal squamous carcinomas, medulloblastoma and breast cancer (Yang et al., 2000, Cloos et al., 2006, Ehrbrecht et al., 2006, Liu et al., 2009 and Uimonn et al., 2014). In addition, in agreement with a contribution of KDM4C to tumor development, inhibition of KDM4C expression reduces cell proliferation (Cloos et al., 2006).

A RGR site in gene coding for growth hormone receptor precursor was located on chromosome 20. Growth hormone receptor (GHR) is receptor for pituitary gland growth hormone involved in regulating postnatal body growth. On ligand binding, it activates the JAK2/STAT5 pathway. Rahmatalla et al. (2011) studied effect of non-synonymous single nucleotide polymorphism (SNP) in exon 8 which leads to a phenylalanine to tyrosine amino acid substitution (F279Y) in the receptor. They predicted the consequences of the F279Y mutation on milk yield, fat, protein, casein, lactose yield and content as well as somatic cell score (SCS), in a German Holstein dairy cattle population. They found that tyrosine variant occurred as the minor allele $(16.5 \%)$ but its substitution effects were $320 \mathrm{~kg}$ ( $305 \mathrm{~d}$ ), $0.02 \mathrm{~kg}$ per day and $0.07 \mathrm{~kg}$ per day for milk, casein and lactose yields, respectively. The same allelomorph had negative effects on fat, protein and casein contents. Besides this, the high-milkyield tyrosine allele was also associated with lower SCS ( $p$ $<0.05$ ). They suggested that F279Y polymorphism possess high potential as a marker for the improvement of milk traits in selection programs. Qin et al. (2007) identified polymorphism in exon 10 of GHR in three cattle breeds (Nanyang cattle, limousin and galloway) and found correlations between GHR gene polymorphism and body size indexes in cattle. A RGR site in DOK6 gene coding for docking protein 6 was located on chromosome 24. DOK proteins are enzymatically inert scaffolding proteins. They provide a tying up platform for the assembly of multimolecular signal complexes. DOK6 promotes Retmediated neurite growth and may affect brain development and maintenance.
RNA-guided recombinase target sites for hyperactivated recombinase beta in bovine genome has been also explored previously in which 436 RGR target sites were identified in bovine genome for recombinase Beta with spacer length five (Pathak et al., 2019).

\section{CONCLUSION}

As RGR target sites are located in several important protein coding genes, RGR platform may expand and revolutionize our ability to explore and alter the genome of livestock and hold great promise for exiting developments in the near future. Current or future generations of RNA guided recombinase may prove useful tools to cleanly delete or integrate DNA for the study or treatment of genetic diseases, or to mediate the precise exchange of genetic material during animal breeding.

\section{ACKNOWLEDGEMENT}

This work was supported by the ICMR through fellowship (Reference: 3/1/3/JRF-2015/HRD).

\section{REFERENCES}

An, B., Xia, J., Chang, T., Wang, X., Miao, J., Xu, L., Zhang, L., Gao, X., Chen, Y., Li, J. and Gao, H. (2018). Genome-wide association study identifies loci andcandidate genes for internal organ weights in Simmental beef cattle. Physiological Genomics. 50: 523-531 doi: 101152/physiolgenomics 000222018.

Asano, S., Nemoto, T., Kitayama, T., Harada, K., Zhang, J., Harada, K., Tanida, I., Hirata, M. and Kanematsu, T. (2014). Phospholipase $\mathrm{C}$-related catalytically inactive protein (PRIP) controls KIF5B-mediated insulin Secretion. Biology Open. 3: 463-474 doi: 101242/bio20147591.

Berryman, S., Clark, S., Monaghan, P. and Jackson, T. (2005). Early Events in Integrin v 6-Mediated Cell Entry of Footand-Mouth Disease Virus. Journal of Virology. 79: 851934 101128/JVI79138519-85342005.

Chaikind, B., Bessen L.J., Thompson, D.B., Hu, J.H. and Liu, R.D. (2016). A programmable Cas9-serine recombinase fusion protein that operates on DNA sequences in mammalian cells. Nucleic Acids Research. 44: 9758-9770.

Cloos, P.A., Christensen, J., Agger, K., Maiolica, A., Rappsilber, J., Antal, T., Hansen, K.H. and Helin, K. (2006). The putative oncogene GASC1 demethylates tri- anddimethylated lysine 9 on histone H3. Nature. 442: 307-311.

Debeer, P., Schoenmakers, E.F., Twal, W.O., Argraves, W.S., De Smet, L., Fryns, J. P. and Van De Ven, W. J. (2002). The fibulin-1 gene (FBLN1) is disrupted in a $t(12,22)$ associated with a complex type of synpolydactyly. Journal of Medical Genetics. 39: 98-104.

Ehrbrecht, A., Muller, U., Wolter, M., Hoischen, A., Koch, A., Radlwimmer, B., Actor, B., Mincheva, A., Pietsch, T. and Lichter, P. (2006). Comprehensive genomic analysis of desmoplastic medulloblastomas: Identification of novel amplified genes and separate evaluation of the different histological components. Journal of Pathology. 208: 554-563. 
Bovine Genome Analysis to Unravel the Location and Feature of Target Sites of RNA-Guided Hyperactivated Recombinase...

Gaj, T., Mercer, A.C., Sirk, S.J., Smith, H.L. and Barbas, C.F. $3^{\text {rd }}$. (2013). A comprehensive approach to zinc-finger recombinase customization enables genomic targeting in human cells. Nucleic Acids Research. 41: 3937-3946.

Gan, Q. F., Zhang, L.P., Li, J.Y., Hou, G.Y., Li, H.D., Gao, X., Ren, H.Y., Chen, J.B. and Xu, S.Z. (2008). Association analysis of thyroglobulin gene variants with carcass and meat quality traits in beef cattle. Journal of Applied Genetics. 49: 251

Ikeda, M., Matsuyama, S., Akagi, S., Ohkoshi, K., Nakamura, S., Minabe, S., Kimura, K and Hosoe, M. (2017). Correction of a disease mutation using CRISPR/Cas9-assisted genome Editing in Japanese black cattle. Scientific Reports. 7: 17827.

Liu, G., Bollig-Fischer, A., Kreike, B., van de Vijver, M.J., Abrams, J., Ethier, S.P. and Yang, Z.Q. (2009). Genomic amplification and oncogenic properties of the GASC1 histone demethylase gene in breast cancer. Oncogene. 28: 4491-4500.

Lu, C., Ward, P.S., Kapoor, G.S., Rohle, D., Turcan, S., AbdelWahab, O., Edwards, C.R., Khanin, R., Figueroa, M.E., Melnick, A., Wellen, K.E., O'Rourke, D.M., Berger, S.L., Chan, T.A., Levine, R.L., Mellinghoff, I.K. and Thompson, C.B. (2012). IDH mutation impairs histone demethylation and results in a block to cell differentiation. Nature. 483: 474-478 doi: 101038/nature10860.

Olivieri, B.F., Mercadante, M.E., Cyrillo, J.N., Branco, R.H., Bonilha, S.F. (2016). Genomic Regions Associated with Feed Efficiency Indicator Traits in an Experimental Nellore Cattle Population. PloS One. 11: e0164390 doi: 101371/ journalpone0164390.

Palgrave, C., Gilmour, L., Lowden, C., Lillico, S., Mellencamp, M. and Whitelaw, B. (2011). Species-specific variation in RELA underlies differences in NF- B activity: A potential role in African swine fever pathogenesis. Journal of Virology. 85: 6008-14.

Pathak, S., Sonwane, A. and Kumar, S. (2019). Exploration of RNAguided recombinase target sites for hyperactivated recombinase beta in bovine genome. Indian Journal of Animal Research. 54(9): 1086-1097.
Qin, Q.M., Xu, S.Z. and Gao, X. (2007). Analysis of the correlations between growth hormone receptor gene polymorphism and body size indexes in cattle. Hereditas. 29: 190-4.

Qu, Z., Gao, F., Li, L., Zhang, Y., Jiang, Y., Yu, L., Zhou, Y., Zheng, H., Tong, W., Li, G. and Tong, G. (2017). Label-free quantitative proteomic analysis of differentially expressed membrane proteins of pulmonary alveolar macrophages infected with highly pathogenic porcine reproductive and respiratory syndrome virus and its attenuated strain. Proteomics. 17: 1700101 doi: 101002/pmic201700101.

Rahmatalla, S.A., Müller, U., Strucken, E.M., Reissmann, M. and Brockmann, G.A, (2011). The F279Y polymorphism of the GHR gene and its relation to milk production and somatic cell score in German Holstein dairy cattle. Journal of Applied Genetics. 52: 459-465.

Saeki, K., Miura, Y., Aki, D., Kurosaki, T. and Yoshimura, A. (2003). The $B$ cell-specific major raft protein, Raftlin, is necessary for the integrity of lipid raft and BCR signal transduction. The EMBO Journal. 22: 3015-3026 doi: 101093/emboj/ cdg293.

Sirk, S.J., Gaj, T., Jonsson, A., Mercer, A.C. and Barbas, C.F. (2014). Expanding the zinc-finger recombinase repertoire: Directed evolution and mutational analysis of serine recombinase specificity determinants. Nucleic Acids Research. 42: 4755-4766.

Uimonen, K., Merikallio, H., Paakko, P., Harju, T., Mannermaa, A., Palvimo, J., Kosma, V.M. and Soini, Y. (2014). GASC1 expression in lung carcinoma is associated with smoking and prognosis of squamous cell carcinoma. Histology and Histopathology. 29: 797-804.

Yang, Z.Q., Imoto, I., Fukuda, Y., Pimkhaokham, A., Shimada, Y., Imamura, M., Sugano, S., Nakamura, Y. and Inazawa, J. (2000). Identification of a novel gene, GASC1, within an amplicon at 9p23-24 frequently detected in esophageal cancer cell lines. Cancer Research. 60: 4735-4739. 